\title{
Aprendizagem em empresas startups: um estudo na Achego, e- commerce de artesanato da Paraíba
}

A aprendizagem é um fenômeno que pode ser explicado a partir das experiências vivenciadas pelos os indivíduos num contexto de atuação. Neste sentido, o objetivo deste trabalho é compreender como ocorre o processo de aprendizagem de empreendedores que atuam em empresas startups. Para tal, buscou-se a partir do delineamento metodológico da Grounded Theory (GT), aproximar-se do fenômeno abordado, desvendando suas nuances e características próprias. A operacionalização do estudo se deu principalmente a partir de entrevista semiestruturada com os empreendedores da Achego uma empresa startup incubada na Fundação Parque Tecnológico da Paraíba e com atuação na cidade de Campina Grande/PB, bem como incluiu documentos e dados online para complementar e fortalecer os achados da investigação. Os resultados apontam que o processo de aprendizagem dos atores em empresas startups se dá em diferentes situações tais como no desenvolvimento das atividades empresariais, na interação com o contexto social, a partir do desenvolvimento de aptidões tecnológicas e conceituais, e a vivência de sentimentos que circundam sua atuação. Além disso, a configuração da identidade organizacional funciona como um plano de fundo capaz de conduzir em seus participantes a necessidade de moldar seus comportamentos, obtendo novas capacidades, conhecimentos e desenvolvendo aptidões necessárias à atuação.

Palavras-chave: Aprendizagem; Empresas Startups; Artesanato; Grounded Theory.

\section{Learning in startup companies: a study at Achego, e-commerce of handicrafts from Paraiba}

\begin{abstract}
Learning is a phenomenon that can be explained from the experiences of individuals in a context of performance. In this sense, the objective of this work is to understand how the learning process of entrepreneurs who work in startups companies occurs. To this end, it was sought from the methodological design of the Grounded Theory (GT), to approach the phenomenon addressed, unveiling its own nuances and characteristics. The operationalization of the study took place mainly from a semi-structured interview with Achego entrepreneurs, a startup company incubated at the Fundação Parque Tecnológico da Paraíba and operating in the city of Campina Grande/PB, as well as including documents and online data to complement and strengthen investigation findings. The results show that the learning process of the actors in startups companies occurs in different situations such as in the development of business activities, in the interaction with the social context, from the development of technological and conceptual skills, and the experience of feelings that surround them your performance. In addition, the configuration of the organizational identity works as a background capable of guiding in its participants the need to shape their behaviors, obtaining new skills, knowledge and developing the necessary skills to act.
\end{abstract}

Keywords: Learning; Startup Companies; Crafts; Grounded Theory.

Topic: Comportamento Organizacional

Reviewed anonymously in the process of blind peer
Received: $16 / 03 / 2020$

Approved: 01/04/2020
Simone Costa Silva

Universidade Federal de Pernambuco, Brasil http://lattes.cnpq.br/5339837796115908

http://orcid.org/0000-0003-1624-2912

monyadm@yahoo.com.br

Marcos André Mendes Primo (iD

Universidade Federal de Pernambuco, Brasil

http://lattes.cnpq.br/0801402521183018

http://orcid.org/0000-0001-8126-9252

marcosprimo0@gmail.com

Eduardo de Aquino Lucena (iD

Universidade Federal de Pernambuco, Brasil

http://lattes.cnpq.br/4896424955173386

http://orcid.org/0000-0001-8441-7337

eaqlucena@yahoo.com.br
Eunice Ferreira Carvalho

Universidade Estadual da Paraíba, Brasil

http://lattes.cnpq.br/0787250920518181

http://orcid.org/0000-0002-2333-1342

elocarvalho21@gmail.com

Jéssica Micaelly Santana do Nascimento Silva (iD)

Universidade Estadual da Paraíba, Brasil

http://lattes.cnpq.br/6942231983740310

http://orcid.org/0000-0002-0453-9324

jessica_nascimento21@hotmail.com

Referencing this:

SILVA, S. C.; PRIMO, M. A. M.; LUCENA, E. A.; CARVALHO, E. F.; SILVA, J. M. S. N.. Aprendizagem em empresas startups: um estudo na Achego, e-commerce de artesanato da Paraíba. Revista Brasileira de Administração Científica, v.11, n.2, p.190-203, 2020. DOI: http://doi.org/10.6008/CBPC2179-684X.2020.002.0013 


\section{INTRODUÇÃO}

Muito se tem falado sobre a gestão organizacional tratar de questões ligadas ao funcionamento de ambientes mutáveis, inovadores e competitivos. Dentro desta perspectiva, são demandadas novas formas de pensar o contexto e a gestão organizacional, através do desenvolvimento de comportamentos mais adequados a um ambiente que propicie tal adaptabilidade e flexibilidade requeridas.

Neste sentido, a aprendizagem passa a ter grande importância na sociedade atual, tornando-se fatorchave para as organizações e seus membros (SPENDER, 2001). Permeada por muitos conceitos e teorias o tema aprendizagem tem sido alvo de muitos estudiosos. Assim, existem muitas concepções acerca do que vem a ser aprendizagem, mas de acordo com Robbins (2009) uma geralmente é mais aceita: qualquer mudança relativamente permanente no comportamento que ocorre como resultado da experiência. Seguindo esta perspectiva, Dewey propõe um conceito de aprendizagem baseado na noção de experiência. A experiência, para este autor, é a relação entre indivíduo e ambientes, "sujeito" e "mundos", que são os termos usados para conotar o indivíduo socializado e o mundo interpretado (ELKJAER, 2009).

Ademais, sabe-se que inovação e tecnologia são aspectos relevantes não apenas em empreendimentos de base tecnológica, mas também em todas as organizações que desejam garantir sua sobrevivência no mercado. A atual configuração ambiental demanda das empresas a capacidade de adequarse às exigências do ambiente onde estão inseridas, sendo um fator essencial para garantir sua sobrevivência no mercado.

No entanto, muitas empresas que operam no contexto de economias emergentes iniciam o seu negócio a partir da tecnologia adquirida de outras empresas. Com isso, ao iniciarem suas atividades, estas organizações não dispõem de capacidades tecnológicas básicas. Portanto, para tornarem-se competitivas elas precisam se engajar em um processo de aprendizagem para construir e acumular sua capacidade tecnológica (FIGUEIREDO, 2004).

O conhecimento proporcionado pelo estudo desses aspectos presentes no dia-a-dia dessas organizações possibilita fornecer base conceitual que pode ao longo do tempo permitir o fortalecimento da capacidade tecnológica, de inovação e de gestão destas empresas, e com isso ajudá-las a se tornar mais competitivas, não somente no contexto das empresas locais, mas também em relação às empresas nacionais e transnacionais. É nesta perspectiva que se insere o presente estudo ao ter como foco a Achego - Ecommerce de Artesanato da Paraíba, uma empresa Startup incubada na Fundação Parque Tecnológico da Paraíba (PaqtcPB).

Diante do exposto, o presente trabalho tem como objetivo principal: Compreender como ocorre o processo de aprendizagem de empreendedores que atuam em empresas startups. Para tal, seguir-se-á o delineamento metodológico da Grounded Theory (GT), buscando obter resposta para o questionamento que orienta o referido estudo, desvendando suas nuances e características próprias (CHARMAZ, 2006).

Nas seções que seguem são apresentadas algumas considerações da literatura sobre os temas que orientam este trabalho, tais como: aprendizagem e empreendedorismo em empresas startup. 
Posteriormente, apresentam-se os procedimentos metodológicos adotados na pesquisa, bem como os resultados alcançados com a investigação do tema, seguido das considerações inferidas sobre o fenômeno estudado.

\section{REVISÃO TEÓRICA}

\section{Aprendizagem e experiência}

O conceito de aprender vem do latim aprenddere, que significa agarrar, apoderar-se de alguma coisa. A aprendizagem é, portanto, considerada aquisição de certo saber com ajuda do outro ou por si só (POZO, 2002). Ainda, pode-se entender a aprendizagem como um processo de mudança instigado por estímulos diversos, mediado por emoções que podem ou não produzir mudança no comportamento da pessoa (FLEURY et al., 2002).

Elkjaer (2004) expõe duas metáforas para aprendizagem, a metáfora da aquisição que compreende um entendimento de aprendizagem como aquisição individual de conhecimento e habilidades e, a metáfora da participação em que a aprendizagem é entendida como participação em comunidades de prática. A mesma propõe ainda uma terceira metáfora, trata-se de uma 'Terceira Via' (The Third Way) para enxergar o fenômeno, tentando atenuar a dicotomia que existe sobre o tema aprendizagem. Nesta aprendizagem inclui tanto a habilidade e a aquisição do conhecimento, quanto a ação e o pensamento e, ainda, acrescenta a emoção e a intuição.

Nesta perspectiva, pode-se afirmar que é possível encontrar uma vasta literatura acerca da aprendizagem, são os muitos os conceitos e teorias sobre este tema, no entanto, para fins deste trabalho será considerada a visão de Dewey (1976) que vincula a aprendizagem à experiência. Na visão deste autor, há conexão orgânica entre o que o mesmo denomina de educação e a experiência pessoal.

Dewey é um dos únicos autores que explicitamente foca sua atenção na aprendizagem a partir da experiência, principalmente na aprendizagem individual dentro das organizações. Na visão deste autor a aprendizagem ocorre a partir da interação social e não pode ser passada de pessoa para pessoa como se fosse um objeto (EASTERBY-SMITH et al., 2011).

Experiência, neste caso, é o conceito de Dewey utilizado para denotar a relação entre o sujeito e mundos, bem como entre ação e pensamento, entre a existência humana e se tornar bem informados sobre si mesmos e sobre o mundo do qual faz parte. Neste caso, o conhecimento é visto como um subconjunto da experiência. Enquanto que a experiência abrange teorias e conceitos e, como tal, torna-se fundação para o conhecimento (ELKJAER, 2009). A experiência é, para Dewey, transação contínua e formação mútua do indivíduo e o ambiente e, o produto deste, portanto, experiência é ao mesmo tempo processo e produto ou o resultado do processo (ELKJAER, 2004).

Sobre a interação esta constitui um dos princípios fundamentais para interpretar uma experiência em sua função e força educativa. Tal princípio atribui direitos iguais aos fatores da experiência: condições objetivas e internas. Assim, qualquer experiência normal é um jogo entre estas duas condições, que tomadas 
em conjunto, ou em sua interação, constituem uma situação. Portanto, o desenvolvimento da experiência se faz por interação do indivíduo com pessoas e coisas, o que torna a educação um processo social (DEWEY, 1976). Isso indica uma visão descentrada do locus e significado da aprendizagem, em que a esta é reconhecida como um fenômeno constituído no que é experienciado, vivido pelo mundo, através de participação periférica na prática social em curso (LAVE, 1991).

Por se tratar de um processo social ao se estudar o fenômeno da aprendizagem deve-se considerar o contexto em que esta ocorre (BERENDS et al., 2010). Contexto (externo e interno) refere-se ao ambiente social, econômico, político e competitivo no qual ocorrem as interações, bem como a estrutura, cultura e o contexto político que permeia o ambiente (PETTIGREW, 1987). Mintzberg et al. (2001) evidenciam que o contexto está relacionado com a situação e os fatores que impactam no ambiente, o que envolve as pessoas, a tecnologia, o sistema organizacional, as mudanças, entre outros aspectos.

Berends et al. (2010) destacam as estruturas sociais e temporais incorporadas ao processo de aprendizagem. Nesta perspectiva, a estrutura social refere-se, sobretudo, aos atores que estão envolvidos no processo de aprendizagem, bem como aspectos como poder e política. Já a estrutura temporal pode ser baseada em diferentes concepções de tempo, o que inclui o tempo relógio, determinado pelo relógio e o calendário, e o tempo evento, que é determinado pela ocorrência de eventos significantes.

Lave (1991) propõe considerar o aprendizado não como um processo de cognição compartilhada que resulta no final da internalização do conhecimento por indivíduos, mas como um processo de se tornar membro de uma comunidade. Assim, desenvolver uma identidade como membro de uma comunidade e tornar-se hábil fazem parte do mesmo processo, em que o primeiro aparece como motivador para moldar e dar significado ao último. Para se debruçar sobre o processo de aprendizagem torna-se necessário considerar além da experiência como base fundamental, aspectos relacionados ao contexto, seja ele interno ou externo, considerando toda a estrutura social e temporal que permeia este fenômeno.

\section{Empreendedorismo, empresas startups e incubadoras}

O empreendedorismo é um processo pelo qual os indivíduos buscam oportunidades, organizam os recursos necessários e, por meio da inovação, abrem seu próprio negócio, assumindo os respectivos riscos e recompensas do empreendimento e satisfazendo suas necessidades e desejos (ROBBINS, 2001).

Para empreender e conseguir manter-se competitivo em um ambiente de tantas incertezas, não basta apenas ter uma ideia interessante. Espírito empreendedor, organização, abertura para correr risco, domínio de conhecimento necessário para conduzir o negócio e abertura à inovação são alguns aspectos que podem fazer toda a diferença. Além disso, a capacidade da organização aprender permite que ela seja mais flexível e adaptável, colaborando para um melhor desempenho e pode conduzi-la ao alcance do sucesso (GARVIN, 1993). Mas, alguns tipos de empreendimentos requerem outras competências, como é o caso das empresas startups.

Startups são empresas nascentes de base tecnológica, que possuem na inovação tecnológica os fundamentos básicos de sua estratégia competitiva. Entre as principais características destes negócios estão 
o caráter de organização temporária e com alto potencial de crescimento, atuam em um ambiente de extrema incerteza, em busca de um modelo de negócios que possa tornar-se repetível e escalável (ABSTARTUPS, 2016; BLANK, 2013). A ideia fundamental de uma Startup é transformar ideias em produtos, medir como os clientes reagem, e, então, aprender se é o caso de abortar a ideia ou perseverar (RIES, 2012). "Muito embora o Brasil não ocupe posição elevada no contexto mundial de inovação tecnológica, o reconhecimento da importância do tema tem resultado na compleição de diversos mecanismos para sua promoção, como institutos de pesquisa, polos, parques e incubadoras tecnológicas" (BELTRAME, 2008). Portanto, "considera-se incubadora de base tecnológica a que abriga empresas cujos produtos, processos ou serviços são gerados a partir de resultados de pesquisas aplicadas, nos quais a tecnologia representa alto valor agregado" (FERIGOTTI, 2005).

A atuação de uma incubadora pode trazer elementos para a dinamização de um arranjo produtivo pela viabilização de empresas com maior agregado tecnológico ou que possam solucionar gargalos produtivos, colocando o conjunto dessas empresas em melhores condições de competição (LAHORGUE, 2008). Neste contexto, a condição de desenvolvimento proporcionada pelas incubadoras dá às empresas bons resultados em termos de aprendizagem que se manifestam em estruturas organizacionais capazes de suportar as exigências impostas pelo mercado (BELTRAME, 2008). Neste sentido, para uma empresa startup, com pouco tempo de atuação e que está inserida num ambiente altamente competitivo e desafiador as incubadoras de empresas significam um suporte muito importante para a viabilização do empreendimento.

\section{METODOLOGIA}

O presente estudo trata-se de uma pesquisa qualitativa. A escolha pela pesquisa qualitativa justificase por não se utilizar de um conjunto de técnicas específicas, mas sim de um enfoque que busca compreender fenômenos sociais (VERGARA, 2009), uma vez que se almeja entender como as pessoas constroem, atribuem significados e interpretam as suas experiências (MERRIAM, 2009; GODOI et al., 2006). O interesse está em compreender os fenômenos sociais, tendo como foco os significados construídos pelos sujeitos a partir das experiências vividas ou sentidas nos diversos contextos. Um importante valor da pesquisa qualitativa é que está permite realizar a descrição e entendimento das interações humanas atuais, significados e processos que constituem a vida real (GEPHART, 2004).

Participaram desta pesquisa os empreendedores da empresa Achego-E-commerce de Artesanatos da Paraíba. A escolha pela referida empresa se deu devido o interesse em investigar uma empresa de base tecnológica e incubada na Fundação Parque Tecnológico da Paraíba (PaqTc). De modo geral, empresas com este perfil atuam em um ambiente de rápidas mudanças o que exige de seus membros a capacidade de adaptação rápida e de desenvolvimento de competências que permitam adequar-se ao ambiente altamente competitivo. Além disso, por se tratar de uma empresa com um foco de atividade inovador e um produto diferenciado (tecnologias para a comercialização de artesanato) o referido estudo pode resultar em resultados que contribuem para o aprofundamento do tema investigado.

Os dados foram coletados por meio de entrevista semiestruturada, dados de documentos, além de 
dados secundários online. No que se refere às entrevistas Gephart (2004) afirma que se trata de uma interação face a face em que o pesquisador propõe questões que o entrevistado responde. No presente trabalho, tais entrevistas foram realizadas a partir de um roteiro semiestruturado elaborado com base no referencial teórico acessado, e tiveram duração aproximada de 40 min cada. Salienta-se que os nomes dos entrevistados não foram identificados por questões de privacidade e respaldo profissional. Assim, nos resultados da pesquisa, estes são identificados como Entrevistado 1 e Entrevistado 2.

Foram produzidas notas de campo no momento de acesso para realização das entrevistas, tais notas têm o intuito de registrar dados relevantes e possíveis dúvidas que surgiram durante a coleta de dados e que deveriam ser sanadas posteriormente. Além disso, documentos como folders e folhetos foram fornecidos pelos próprios participantes da pesquisa, buscando melhor ilustrar fatos e acontecimentos mencionados durante as entrevistas. Dados secundários online foram levantados por meio da Internet, buscando fortalecer evidências e sanar algumas dúvidas sobre o assunto investigado. De acordo com Santos (2009) a pesquisa documental é uma das técnicas mais antigas na história do pensamento humano, tendo atualmente importante desenvolvimento pela digitalização e ampliação de acesso online. Conforme propõe Yin (2010) "o uso mais importante dos documentos é para corroborar e aumentar a evidência de outras fontes". Nesta perspectiva, esses dados foram encontrados, sobretudo, em sites de organizações parceiras como Prefeitura de Campina Grande, Governo do Estado da Paraíba, Fundação PaqtcPB, Sebrae, além de jornais, revistas e sites de notícias locais.

Para a apreciação dos resultados utilizou-se a análise de dados qualitativa, seguindo a metodologia da Grounded Theory (CHARMAZ, 2009) a qual ocorreu a partir dos seguintes momentos: no primeiro realizouse a transcrição das entrevistas, leitura e releitura do protocolo da entrevista. No segundo momento procedeu-se a codificação Inicial (linha a linha) - a partir de que foram surgindo algumas palavras que explicavam acontecimentos, ações e se repetiam (coincidiam) nas falas. No terceiro, realizou-se a codificação focada momento em que algumas palavras foram destacadas para possivelmente serem transformadas em categorias. No quarto momento foi construído um quadro com uma proposta inicial de categorias, buscando distribuir os códigos nestas categorias. Com isso, algumas categorias propostas se fundiram, outras foram renomeadas ou deixaram de existir, com o intuito de buscar a saturação categorial. A Figura 1 expõe o passoa-passo da condução deste estudo.

Durante a análise de dados se seguiu o Método de Comparação Constante (GLASER et al., 1967; citado por CHARMAZ, 2006), procurando comparar diferentes dados, incidentes e categorias e, desta forma encontrar similaridades e diferenças. Ainda, foram confeccionadas pequenas notas (memo writing) com o intuito de registrar comparações, conexões, conjecturas e novas ideias que surgem durante o processo de análise e que podem explicar e preencher gaps entre as categorias propostas. Estas notas também são um importante passo antes da confecção do relatório final de pesquisa. Foram eleitas cinco categorias propostas para explicar o evento estudado, tais categorias são resumidas no Quadro 1 o qual traz também um resumo explicativo de quais eventos, ações e incidentes compõem cada categoria teórica. 


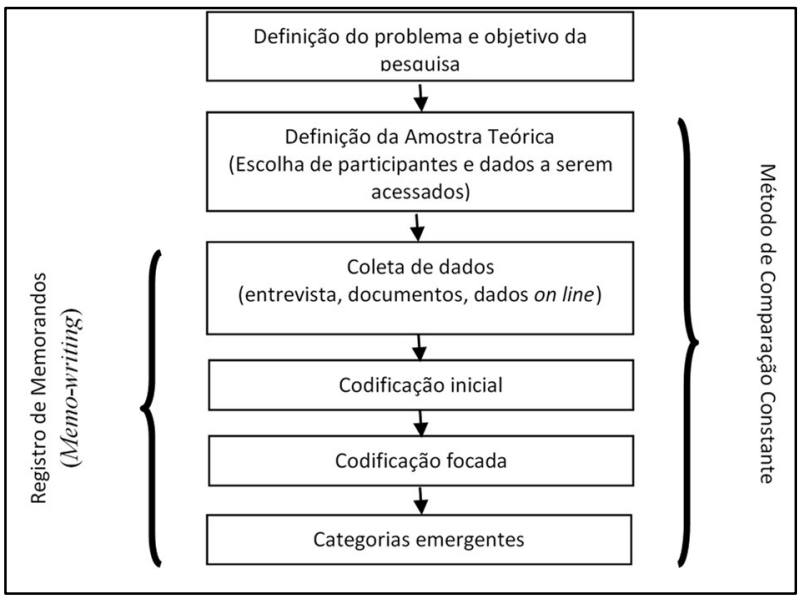

Figura 1: Esquema de condução do estudo (passo-a-passo).

Quadro 1: Categorias emergentes e suas características.

\begin{tabular}{|l|l|}
\hline \multicolumn{1}{|c|}{ Categoria } & \multicolumn{1}{c|}{ Descrição } \\
\hline Gerenciando o Contexto & $\begin{array}{l}\text { Aspectos do ambiente interno e externo onde se dão as ações organizacionais: pessoas, clientes, } \\
\text { parceiros, outras organizações, mudanças ambientais, políticas de incentivos. }\end{array}$ \\
\hline Atuando no Cotidiano & $\begin{array}{l}\text { Todas as atividades-chave realizadas pela empresa, tais como: negociação, consultoria, } \\
\text { intervenção nos produtos, organização e participação em eventos, planejamento, divisão de } \\
\text { tarefas e reuniões. }\end{array}$ \\
\hline $\begin{array}{l}\text { Desenvolvendo Aptidões } \\
\text { Tecnológicas e Conceituais }\end{array}$ & $\begin{array}{l}\text { Disposição inata ou adquirida necessárias para atuação: conhecimentos sobre E-commerce, } \\
\text { market place, site, marketing digital, empreendedorismo, busca de informações, aprendizagem } \\
\text { por tentativa e erro, troca de experiência. }\end{array}$ \\
\hline Vivenciando Sentimentos & Necessidade de interação, espírito empreendedor, gostar do que faz, ter sorte. \\
\hline $\begin{array}{l}\text { Configurando a Identidade } \\
\text { Organizacional }\end{array}$ & $\begin{array}{l}\text { Características mutantes da empresa ao longo do tempo. Startup mas, ao mesmo tempo } \\
\text { tradicional, de cunho social, proativa, que busca inovar. }\end{array}$ \\
\hline
\end{tabular}

Ao longo do processo de análise, buscou-se preencher os gaps entre as categorias, tentando reduzilas como propõem Merriam (2010) ao afirmar que as categorias não devem ser numerosas. Seguindo-se, uma vez que as categorias emergiram explicando o evento investigado, tornou-se necessário seguir com a descrição destas, expondo suas propriedades e características, o que forma um texto que a partir de uma abordagem interpretativa busca mais do que explanar e prever um fenômeno, ter um olhar diferenciado sobre um determinado fenômeno. Ademais, foram propostas figuras (diagramas) para melhor ilustrar os achados da pesquisa, facilitando a compreensão do fenômeno estudado.

\section{RESULTADOS E DISCUSSÃO}

Nesta seção são descritos os principais achados do estudo no que se refere ao processo de aprendizagem em empresas Startups o que pode ser explicado a partir de cinco categorias emergentes, referindo-se estas ao contexto organizacional, as ações realizadas diariamente, o processo de desenvolvimento de aptidões tecnológicas e conceituais, os sentimentos vivenciados pelos empreendedores participantes da pesquisa, além de aspectos relacionados à identidade organizacional.

\section{Gerenciando Contexto}

A empresa Achego - E-commerce de Artesanatos da Paraíba trata-se de uma empresa em processo de incubação na Fundação Parque Tecnológico, que está no mercado há três anos, portanto, no início de suas atividades. A empresa é denominada por seus gestores como uma empresa inovadora e que busca 
crescimento e reconhecimento no mercado. A consultoria aos artesãos sobre design de produtos e a inserção e comercialização destes no mercado internacional são as principais atividades realizadas pela empresa.

No contexto de atuação da empresa destaca-se, sobretudo, a necessidade de interação com diversas pessoas, seja no contexto interno ou externo à organização. No que se refere ao contexto interno a troca de informações com os clientes, neste caso, os artesãos, foi crucial, inclusive, para decisão de levar à frente a ideia do empreendimento. $O$ que pode ser confirmado na fala de um dos entrevistados:

Partindo de um produto que eu já tinha feito, inicialmente, fomos na Vila do Artesão para ver qual matéria prima que melhor se adequava ao processo de fabricação do meu produto que era bem manual. Aí na vila do artesão eles começaram a falar qual era o produto que melhor se adequava e começaram a desabafar também quais eram os problemas de lá [...] A partir disso, ele (o sócio) teve o time de tentar transformar esse problema numa solução através da nossa empresa. (ENTREVISTADO 01).

Com relação ao contexto externo, destaca-se, principalmente, a interação com outras organizações que foram de elevada importância para o estabelecimento da empresa. Desde o início, pessoas inseridas em outras organizações como o Parque tecnológico, a Agência Municipal de Desenvolvimento (AMDE), coordenadores da Vila do Artesão (local onde estão localizados os artesãos) foram cruciais para a viabilidade do negócio. Além disso, a exportação de produtos para locais como os Estados Unidos e Europa só foi possível devido a atuação de parceiros no exterior.

Eu já conhecia uma pessoa lá um coordenador administrativo de lá, mas o que realmente facilitou foi essa ligação com o Parque Tecnológico, ficamos também parceiros deles e até a parceria com a Artesa, que é uma cooperativa de couro veio a partir deles também, dentre outros que eles ainda querem fazer parceria com a gente (ENTREVISTADO 01).

No mais, a busca por oportunidades de expansão da atuação da empresa para outros municípios do estado, a procura por novas parcerias bem como o monitoramento das mudanças ambientais e do surgimento de novos concorrentes, além das políticas de incentivos para o setor, representam a intenção da Achego em conhecer e acompanhar os movimentos do contexto onde a empresa está inserida.

Neste caso, empreendedores startups ao realizar suas atividades empresariais diárias vivenciam situações que os conduzem à aprendizagem (aprendizagem a partir da experiência). De acordo com Dewey é essa relação sujeito-mundos que torna a experiência possível (ELKJAER, 2009) e apartir daquilo que foi experienciado os atores são capazes de moldar seu comportamento futuro, agindo de maneira considerada mais adequada em situações futuras semelhantes.

\section{Atuando no Cotidiano}

Entre as atividades desenvolvidas pela empresa destaca-se a consultoria sobre o design dos produtos artesanais, a construção do site para realizar o e-commerce (primeira e principal atividade da empresa) e a capacitação de artesãos para exportação dos produtos. Ao longo da atuação da empresa a organização de eventos foi algo que foi acrescentado a este portfólio de atividades, o que aconteceu de forma não planejada, exigindo um esforço maior para operacionalizar tal atividade.

O monitoramento dos eventos que ocorrem no país voltados para o setor de atuação, assim como a 
participação nestes eventos, tornou-se, com o tempo, uma atividade cotidiana e de extrema necessidade uma vez que nestes eventos é possível trocar experiências, realizar parcerias e divulgar o nome da empresa já que a mesma tem o intuito de expandir seus negócios. Isso foi destacado por um dos entrevistados: "As consultorias que a gente dá é em relação ao design, marketing digital, construção de site e até a intervenção no design, com a qualificação dos produtos, a capacitação dos artesãos em novos produtos" (Entrevistado 01).

Além disso, outras atividades fazem parte do contexto de atuação da empresa como a necessidade de realizar planejamento, fazer reuniões, dividir tarefas, buscar novos mercados, parceiros e clientes. Tais atividades que são comuns a todas as empresas, neste caso, devido ao número reduzido de pessoas que formam a organização (apenas duas) requer, de seus participantes, habilidades multifuncionais.

Neste sentido, a interação com o contexto social, o que envolve pessoas, organizações e suas diversas interações, consiste em outra situação que possibilita a aprendizagem dos atores, sendo esta uma das possibilidades de elevada importância (aprendizagem informal). "Indivíduos ganham experiência como resultado de como eles vivem suas vidas e como eles se associam com os outros" (BRANDI et al., 2011). Portanto, a troca de experiências a partir do contato com o outro indivíduos, entre outros processos de transação no contexto são situações desencadeadoras da aprendizagem

\section{Desenvolvendo Aptidões Tecnológicas e Conceituais}

Desde o início da atuação dos empreendedores houve a necessidade de lidar com diversas ferramentas ligadas a Tecnologia da Informação (TI). Mesmo um dos sócios tendo conhecimento sobre algumas delas, os empreendedores foram impulsionados a desenvolver habilidades para lidar com tais tecnologias. Assim, criação do site para viabilizar o e-commerce, a produção de um pitch (vídeo que mostra em poucos minutos a proposta de criação da empresa) e o conhecimento de ferramentas do marketing digital foram algumas das atividades ligadas à área de Tecnologia da Informação (TI) que tiveram que ser desenvolvidas e, para tal, os empreendedores precisaram buscar aprender, buscar capacitação. 0 entrevistado 2 comentou sobre essa temática: 'Eu tinha feito um curso de web designer e tinha um blog, trabalhava um pouco nessa área de Internet. Eu gosto dessa área de computação, informática, aí eu fui fazer o curso para complementar, como hobby mesmo'.

Conhecimentos relacionados à gestão de empresas foi um dos grandes desafios de aprendizagem vivenciados pelos empreendedores uma vez que nenhum deles tinha qualquer formação na área, no entanto, se viram obrigados a conhecer ferramentas de gestão e realizar atividades como planejamento, organização e controle. "A gente precisou do plano de negócios e nós buscamos estudar sobre o assunto e tudo mais para formular a empresa e confeccionar o plano de negócios" (ENTREVISTADO 02).

Para isso, um dos entrevistados comentou que durante a formação universitária algumas disciplinas abordam estes conceitos, como também foi ressaltada a atuação do Parque Tecnológico em dar apoio e consultoria sobre a gestão da empresa. "O Parque fornece consultoria e tudo mais e na universidade também tem algumas disciplinas que a gente paga como: gestão da qualidade, ergonomia, engenharia econômica, 
que são mais voltadas para essa parte de gestão" (ENTREVISTADO 02).

Cabe ressaltar que para aprender sobre os temas que necessitavam os empreendedores buscavam, principalmente, estudar sozinho, com o uso da Internet, buscando material que abordasse os temas requeridos, ou trocando informações entre eles ou com outras pessoas. Além disso, buscaram aprender a partir das experiências vividas na prática.

É o seguinte, surgiu uma ideia inovadora e a gente não tinha certos parâmetros e muitas vezes a gente ia por tentativa e erro, fazer uma coisa, ver como acontecia, como era o ambiente daquela solução que a gente estava compondo e mudar ou não. [...] A gente busca aprender através da Internet, através dos parceiros, de ler muito, a gente procura artigos, coisas que saem sobre a área da gente. (ENTREVISTADO 02).

Hoje eu posso dizer que estudei muito, hoje eu sei bem mais o que envolve toda essa questão do artesanato e o meu sócio também estudou muito porque ele é bem curioso sobre marketing, inovação e até design. (ENTREVISTADO 01).

Com isso, percebe-se que para o exercício das atividades cotidianas tais empreendedores sentem-se impulsionados a desenvolver aptidões tecnológicas e conceituais, ou seja, precisam aprender sobre como lidar com determinadas ferramentas de Tecnologia da Informação, bem como dominar conhecimentos de Gestão (aprendizagem formal e não formal), o que constitui uma nova possibilidade de aprendizagem.

A literatura sobre aprendizagem considera que aquisição de certo saber pode ocorrer individualmente ou com a interação com outras pessoas (POZO, 2002). Além disso, a experiência a partir de teorias e conceitos produz uma fundação para o conhecimento (ELKJAER, 2009). Assim, a aprendizagem pode se dar de modo formal, está tem base educacional e segue normas, resoluções e, portanto, precisa de comprovação por meio de certificados, diplomas, entre outros mecanismos. Já a aprendizagem não formal, também tem base educacional, no entanto, não precisa existir comprovação, pode ser por iniciativa do indivíduo a partir da leitura e busca de informações.

\section{Vivenciando Sentimentos}

$\mathrm{Na}$ atuação como empreendedor alguns sentimentos são geralmente vivenciados pelos indivíduos que estão à frente de seus negócios. Além disso, algumas características pessoais são requeridas para uma boa atuação no mundo do empreendedorismo, tais como: Ser propenso a correr riscos, lidar com incertezas, ter feeling para o negócio, trabalhar sobre pressão e intuição aguçada. Conhecendo tais necessidades os empreendedores a frente da empresa estudada citaram alguns sentimentos vividos que foram muito importantes para o processo de implantação e desenvolvimento da empresa e seu processo de aprendizagem.

Sentimentos como gostar do que faz, sentir-se realizado com o trabalho, ter sorte, ter espírito empreendedor e até sentimento de frustração foram citados algumas vezes durante as entrevistas realizadas. Além disso, os sócios empreendedores destacam que cada um deles têm competências individuais que foram categóricas para o desenvolvimento de suas tarefas:

É como a gente sempre diz, eu sou o coração, a sensibilidade, a pele e ele é a questão do negócio, da inovação da tecnologia e tudo mais. Ele tinha essa veia de empreendedorismo mais do que eu [...] Porque artesanato é isso, sensibilidade, você tem que olhar e se emocionar. Sentir a alma do artesão, de sentir toda uma estrutura, toda a história dele, 
porque está contido ali naquele produto. (ENTREVISTADO 01).

Preocupação com o futuro da empresa no que se refere à expansão das atividades e com isso a inserção de outras pessoas no negócio também, podem ser destacados. Apesar de afirmar que têm ciência da necessidade de introduzir outras pessoas, quer sejam funcionários ou sócios, devido ao aumento na demanda das atividades da empresa, os empreendedores mostraram-se preocupados com este momento: "Futuramente a gente vai ter que abrir mão de uma coisa que a gente não queria que é colocar outras pessoas na sociedade" (ENTREVISTADO 01). "A gente até que queria uma terceira pessoa na sociedade, mas que vestisse a camisa e que estivesse disposto a correr risco e atuar nesta área" (ENTREVISTADO 02).

Com isso, a aprendizagem também ocorre a partir dos vários sentimentos vivenciados ao longo de sua trajetória, sejam eles positivos ou negativos. Estes sentimentos podem ao longo do tempo moldar seu comportamento futuro. Tal perspectiva corrobora com Elkaer (2004) quando propôs a terceira metáfora para abordar a aprendizagem - a Terceira Via (The Third Way) - reconhecendo que intuição e emoção são importantes desencadeadores do desenvolvimento da experiência e do conhecimento.

\section{Configurando a Identidade Organizacional}

Apesar do pouco tempo de atuação a Achego já passou por algumas mudanças na sua estrutura de atuação. Inicialmente, antes mesmo de montar o negócio um dos sócios pretendia apenas criar um site para vender seus produtos. Com a busca de informações e a interação com outras pessoas (neste caso, os artesãos) os empreendedores reformularam a ideia e decidiram criar o e-commerce para comercialização dos produtos destes artesãos, fazendo uma intermediação entre os produtores e os clientes finais.

Atualmente a empresa passa por um novo momento de reconfiguração de suas atividades em que pretende deixar de ser um site para e-commerce de produtos artesanais, tornando-se uma plataforma de Market Place (ambiente de varejo online onde diversos lojistas ofertam seus produtos em um único local). Com isso, a interação do cliente final será diretamente com o produtor via plataforma. A Achego permanecerá com as atividades de consultoria, intervenção no design dos produtos, entre outras atividades, como destacado por um dos participantes da pesquisa "A gente está passando por um momento de transição da empresa, de modificar um pouco o modelo de negócio" (ENTREVISTADO 02).

Devido às características do trabalho desempenhado pela organização estar muito voltada para a área de TI, mas também por ter uma atuação voltada para o bem-estar social e a cooperação, sua identidade, na visão dos entrevistados, permeia o campo do social e do tecnológico ao mesmo tempo. "A gente é uma empresa com esse cunho também social, mas a gente é uma Startup - que é uma empresa que sempre está à procura de um modelo de negócio que seja escalável" (ENTREVISTADO 02).

Essa identidade ainda não está bem estabelecida e também inclui o fato de que, ao mesmo tempo em que lida com ferramentas como marketing digital, market place, e-commerce, entre outras terminologias tecnológicas, a empresa também atua como uma consultoria tradicional. Acredita-se que o grande diferencial da Achego seja exatamente este. Trata-se tanto de uma empresa de base tecnológica, mas também tem seus pilares na atuação empresarial tradicional e social/cooperativa, como destacou um dos 
participantes: "Como startup a gente ainda está em busca desse modelo que seja escalável e tudo mais, mas, além disso, a gente também atua como uma empresa mais tradicional de consultorias" (ENTREVISTADO 02)

Além do mais, há a busca pelo reconhecimento da relevância do trabalho desenvolvido pela organização, de sua razão de existir, e isto está relacionado à necessidade de ver aquilo que foi feito até o momento, as dificuldades vivenciadas, todas as barreiras transpostas, como algo que realmente valeu a pena.

Eu espero que a Achego seja uma empresa realmente reconhecida por fomentar o artesanato brasileiro, por ser uma empresa de Marketing digital que trabalha com isso, que está presente em várias associações, cooperativas, em várias cidades e estados, estruturando $o$ artesanato, mas que não seja apenas um artesanato, mas $O$ artesanato brasileiro, conhecido, valorizado, bem apresentado para todo Brasil. (ENTREVISTADO 01).

A configuração da identidade organizacional ao longo do tempo, num processo de transição, aperfeiçoamento e mudança de aspectos desta identidade funciona como um plano de fundo capaz de conduzir em seus participantes à necessidade de moldar seus comportamentos, obtendo novas capacidades, conhecimentos e desenvolvendo aptidões necessárias à atuação. Segundo Lave (1991) a construção de identidade é também uma maneira de falar da constituição da própria comunidade através da atividade de seus praticantes, envolve reconhecimento e validação por outros participantes da mudança da prática de novos e velhos hábitos. Desta forma, a característica transitória da identidade organizacional tende a dar suporte à aprendizagem dos indivíduos ali envolvidos. Na Figura 2 buscou-se sintetizar os achados da pesquisa e ao mesmo tempo mostrar de modo simbólico como ocorre o fenômeno estudado.

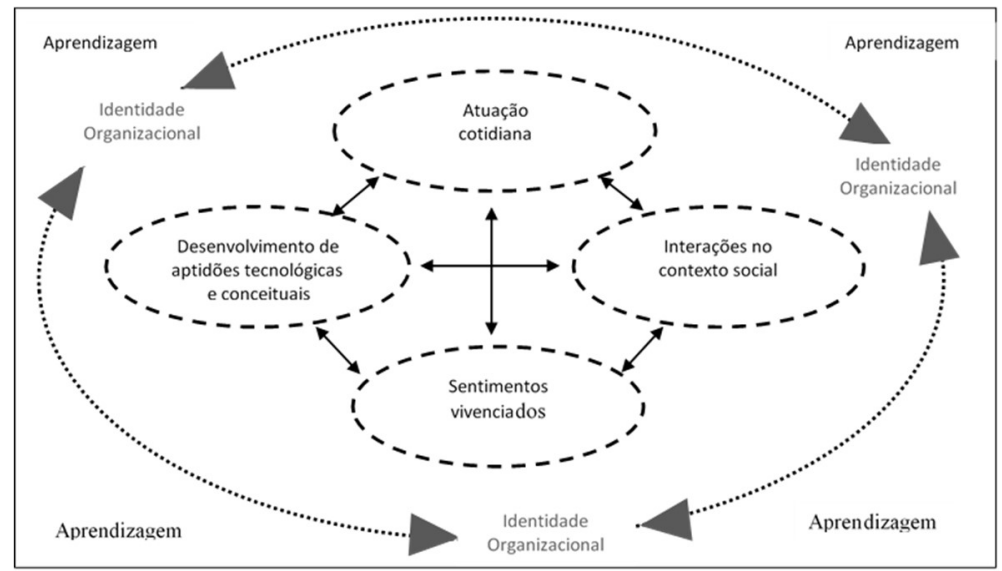

Figura 2: Processo de aprendizagem de empreendedores startups

\section{CONCLUSÕES}

O objetivo deste estudo consistiu em compreender como ocorre o processo de aprendizagem de empreendedores que atuam em empresas startup. Algumas limitações do estudo perpassam o fato de que empreendimentos startups são geralmente pequenas empresas, com um número limitado de participantes que possam relatar a experiência do fenômeno, o que dificulta a análise do tema abordado a partir da metodologia de pesquisa empregada (Grounded Theory). Por outro lado, o fato de serem empresas que atuam em um ambiente de altamente competitivo, dinâmico e que requer uma postura diferenciada por parte de seus empreendedores, torna o estudo destas empresas bem estimulante.

No que se refere ao objeto de estudo proposto, neste caso a aprendizagem de empreendedores 
startups, alguns achados precisam ser considerados.

Os resultados encontrados sugerem que o processo de aprendizagem dos empreendedores no contexto de empresas startups se dá, principalmente, nas atividades empresariais cotidianas e a partir da interação com o contexto social. Para exercer estas atividades diárias os empreendedores são levados a desenvolver competências tecnológicas e conceituais, ligadas, sobretudo, às tecnologias da informação e capacidade de gestão, o que configura mais uma oportunidade de aprendizagem. E ainda, no contexto abordado, a aprendizagem também ocorre a partir dos sentimentos, positivos ou negativos, vividos pelos atores durante sua trajetória à frente da empresa.

Além disso, por se tratar de uma organização com pouco tempo de atuação, portanto, uma empresa jovem, e que sua identidade ainda se encontra em processo de formação, necessitando de mudanças e adequações desta identidade, a configuração da identidade organizacional aparece como um plano de fundo que conduz e molda o processo de aprendizagem dos atores, levando-os a desenvolver novos comportamentos, obter outras capacidades, conhecimentos e desenvolver novas aptidões.

Assim, no contexto estudado, o aprender de empreendedores startups, aproxima-se das teorias da aprendizagem que consideram este um fenômeno social em que cognição, sentimento e ação são importantes desencadeadores do desenvolvimento da experiência e do conhecimento.

\section{REFERÊNCIAS}

ABSTARTUPS. Associação Brasileira de Startups. Manual sobre conceitos, metodologias e investimentos em startups. ABSTARTUPS, 2016.

BERENDS, H.; LAMMERS, I.. Explaining discontinuity in organizational learning: A process analysis. Organization Studies, v.31, n.08, p.1045-1068, 2010. DOI: https://doi.org/10.1177/0170840610376140

BELTRAME, A.. Ensinagem e aprendizagem em incubadora tecnológica: um estudo de caso na incubadora tecnológica de Caxias do Sul. Dissertação (Mestrado em Administração) Universidade de Caxias do Sul, Caxias do Sul, 2008.

BLANK, S.. The four steps to the epiphany. K\&S Ranch, 2013

BRANDI, U.; ELKJAER, B.. Organizational learning viewed from a social learning perspective. In: EASTERBY-SMITH, M.; LYLES, M.. Handbook of organizational learning and knowledge management. 2 ed. Chichester: John Wiley and Sons, 2011. p.23-41. DOI: https://doi.org/10.1002/9781119207245.ch2

CHARMAZ, K.. Constructing Grounded Theory. 2 ed. London: Sage Publications, 2006.

DEWEY, J.. Experiência e Educação. 2 ed. São Paulo: Nacional, 1976.

EASTERBY-SMITH, M.; LYLES, M.. The evolving field of organizational learning and knowledge management. In: EASTERBY-SMITH, M.; LYLES, M.. Handbook of organizational learning and knowledge management. 2 ed. Chichester: John Wiley and Sons, 2011. p.1-20. DOI: http://doi.org/10.1002/9781119207245.ch1
ELKJAER, B.. Pragmatism - A learning theory for the future In: ILLERIS, K.. Contemporary Theories of Learning: Learning Theorists: in Their Own Words. Taylor \& Francis e-Library, 2009.

ELKJAER, B.. Organizacional Learning. The 'Third Way'. Management Learning, v.35, n.4, p.419-434, 2004. DOI: https://doi.org/10.1177/1350507604048271

FERIGOTTI, C. M. S.. Aprendizagem e capacidade tecnológica: O Papel da Incubadora. In: SEMINÁRIO LATINOIBEROAMERICANO DE GESTIÓN TECNOLÓGICA, 9. Anais. Salvador: ALTEC, 2005.

FLEURY, M. T. L.; OLIVEIRA JUNIOR, M. M.. As Pessoas na Organização. São Paulo: Gente, 2002.

FIGUEIREDO, P. N.. Aprendizagem tecnológica e inovação industrial em economias emergentes: uma breve contribuição para o desenho e implementação de estudos empíricos e estratégias no Brasil. Revista Brasileira de Inovação, v.3, n.2, 2004. DOI: https://doi.org/10.20396/rbi.v3i2.8648901

GARVIN, D.. Building a learning organization. Harvard Business Review, p.78-91, 1993.

GEPHART, R. P.. Whats is qualitative research and why is it important?. Academy of Management Journal, v.47, n.4, p.454-462, 2004. DOI:

https://doi.org/10.5465/AMJ.2004.14438580

GODOI, C. K.; BALSINI, C. P. V.. A pesquisa qualitativa nos estudos organizacionais brasileiros: uma análise 
bibliométrica. In: GODOI, C. K.; BALSINI, C. P. V.; MELLO, R. B.; SILVA, A. B.. Pesquisa qualitativa em estudos organizacionais: paradigmas, estratégias e métodos. São Paulo: Saraiva, 2006

LAHORGUE, M. A.. Incubadoras de empresas no Brasil: quadro a partir das avaliações realizadas no período de 2000-2007. In: JORNADAS LATINO-AMERICANAS DE ESTUDOS SOCIAIS, DAS CIÊNCIAS E DAS TECNOLOGIAS, 7 Anais. Rio de Janeiro: ESOCITE, 2008.

LAVE, J.. Situating Learning in Communities of Practice. In: LAVE, J.; WENGER, E.. Situated learning: legitimate peripheral participation. Cambridge: Cambridge University Press, 1991.

MERRIAM, S. B.. Qualitative research: a guide to design and interpretation. San Francisco: Jossey-Bass, 2009.

MINTZBERG, H.; QUINN, J. B.. O processo da estratégia. 3 ed. Porto Alegre: Bookman, 2001.

PETTIGREW, A. M.. Context and action in transformation of the firm. Journal of Management Studies, v.24, n.6, p.649-
670, 1987. DOI: https://doi.org/10.1111/j.14676486.1987.tb00467.x

POZO, J. I.. Aprendizes e Mestres: a nova cultura da aprendizagem. Porto Alegre: Artes Médicas, 2002.

ROBBINS, S. P.. Fundamentos do comportamento organizacional. 8 ed. São Paulo: Pearson Prentice Hall, 2009.

RIES, E.. A Startup enxuta. São Paulo: Leya Brasil, 2012.

SANTOS, T. S.. Do artesanato intelectual ao contexto virtual: ferramentas metodológicas para a pesquisa social. Sociologias, Porto Alegre, v.11, n.21, p.120-156, 2009. DOI: http://dx.doi.org/10.1590/S1517-45222009000200007

SILVA, A. B.. Pesquisa qualitativa em estudos organizacionais: paradigmas, estratégias e métodos. São Paulo: Saraiva, 2006.

VERGARA, S. C.. Projetos e relatórios de pesquisa em administração. 10 ed. São Paulo: Atlas, 2009.

YIN, R. K.. Estudo de caso: planejamento e métodos. 4 ed. Porto Alegre: Bookman, 2010.

A CBPC - Companhia Brasileira de Produção Científica (CNPJ: 11.221.422/0001-03) detém os direitos materiais desta publicação. Os direitos referem-se à publicação do trabalho em qualquer parte do mundo, incluindo os direitos às renovações, expansões e disseminações da contribuiç̃o, bem como outros direitos subsidiários. Todos os trabalhos publicados eletronicamente poderão posteriormente ser publicados em coletâneas impressas sob coordenação da Sustenere Publishing, da Companhia Brasileira de Produção Científica e seus parceiros autorizados. Os (as) autores (as) preservam os direitos autorais, mas não têm permissão para a publicação da contribuição em outro meio, impresso ou digital, em português ou em tradução. 